\title{
Interaction Between Technology With Learning Activity
}

\author{
Sihkabuden \\ Malang State University \\ Corresponding e-mail: $\underline{\text { Sihkabuden.fip@um.ac.id }}$
}

\begin{abstract}
The study aims to describe the interaction between technology in learning as a learning experience, in the context of the field of professional practice for undergraduate education technology. Our main focus is the meaning and essence of the learning experience, on the integration of technology in learning. Research supports the development of undergraduate educational technology professional skills in diverse academic and workplace learning environments. The underlying view is the nature of self-change, professional behavior, and the requirement for entry-level practice, which is effective in relevant professional fields.
\end{abstract}

Keywords: Technology Integration, Education Technology Profession

\section{INTRODUCTION}

Cloud computing is the latest computing paradigm. Gluria's cloud computing paradigm (2013) is an optimal mix of hardware and software as a virtual service resource so users are free from the burden of worry about managing the service system. Migrating Web applications to Cloud Computing services and integrating Cloud computing services into infrastructure is something that is not easy. This led to a new paradigm that often requires paradigm innovation and practice at all levels: technical, cultural, legal, regulatory, and social.

Cloud Computing offers a measurable dynamic learning resource. Learning resources provided by cloud computing services according to reddy (2011) is a web service that guarantees many economic benefits and has the advantage of being distributed among its users. Cloud computing, created in late 2007 , now appears as a hot topic because of the ability to offer dynamic and flexible technology as an Information Technology infrastructure, computing environments and configured software services. As reported in the Google trend shown in Figure. 2, Cloud computing (yellow line), virtualization technology (yellow line), has exceeded the Grid computing (red line). Many projects in industry and academia have started, Such as IBM and the EU for Cloud computing, Amazon Elastic Compute Cloud, IBM Blue Cloud, Cloud scientific projects such as Nimbus and Stratus, and Open Nebula. HP, Intel Corporation and Yahoo! Inc. recently announced the establishment of multi-data, global center, open source Cloud computing for industry, research and education.

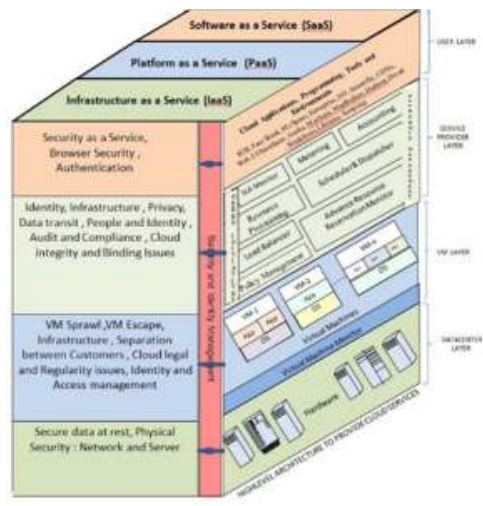

Figure 1. Security Architecture of Cloud Computing. (Reddy.2011)

In general there is still a widely accepted definition for Cloud computing although Cloud computing practices have attracted much attention. Some reasons lead to this situation: Cloud computing involves researchers and engineers from diverse backgrounds, for example, Grid computing, software engineering and databases. They work on Cloud computing from a different point of view. Technology that enables Cloud computing is still evolving and progressing, for example, Web 2.0 and Service Oriented Computing. Cloud Computing is still lacking of large-scale deployment and usage, which will ultimately justify the concept of Cloud computing. 


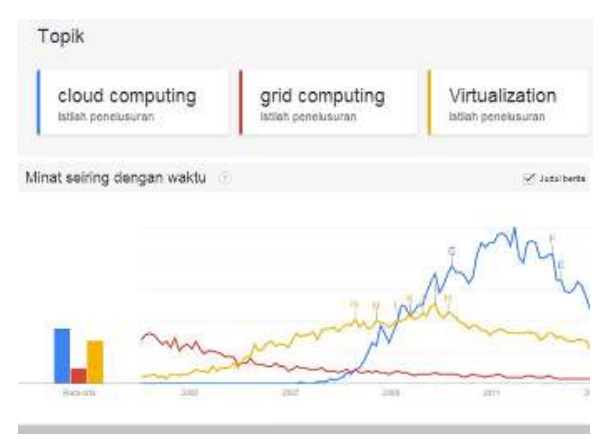

Figure 2. Google Trend Report

Department of Educational Technology State University of Malang is an institution that always intersect with the culture of global learning behavior. Global culture is always influenced by strong culture of developed countries such as countries in the Americas such as the United States and Canada, countries in continental Europe such as Britain and Germany, countries in the Asian continent such as Japan and China. Cultural friction is experienced by undergraduate students of the Department of Education Technology State University of Malang is characterized by the use of global learning resources. Source Library, Lecturer, access url address, broadcast mostly a global cultural product. Global learning behavior is a learning behavior that is no longer limited by classrooms. More broadly global culture has the dimension of freedom of learning by using the optimal learning media such as correspondence samples, learning by using broadcasting devices such as radio and television, learning by using networking facilities such as LAN, WAN, intranet, internet and others. Department of Educational Technology State University of Malang is majoring in the field of scientific education and learning technology also gained a global cultural influence. It is characterized by the use of information and communication technology in learning activities as well as in searching for learning resources. Information and communication technology has always been a topic of discussion and simultaneously used as a tool in in searching, processing, managing, displaying and delivering learning resources.

Department of Education Technology State University of Malang continually strive to develop information and communication technology as a form of service to lecturers and students. These efforts are demonstrated through the provision of various information and communication technology facilities in the form of LAN installation provision, installation of Web-site of Department of Educational Technology State University of Malang, Provision of Main Server Hardware, giving students access to learning resources through certain channels, and to support learning activities Especially the need for learning resources, within the Department of
Educational Technology State University of Malang has installed network facilities,

Department of Educational Technology State University of Malang has a commitment to the development of information and communication technology directed by the empowerment of all facilities available in the Department of Education Technology State University of Malang in turn will support the department in carrying out its programs, including the provision of learning services via the web. Department of Education Technology State University of Malang has a desire on the learning process through the web in order to facilitate the department in controlling academic activities, related to lectures and presentation of courses. Students' attention to learning resources can be improved by increasing the academic atmosphere of the campus environment (Runtuwane, 2007). Department of Educational Technology State University of Malang has developed a department into Learning Services Service Center on the Internet. On a large scale this service is part of the Internet servises Provider (ISP) . Development by the Department of Educational Technology State University of Malang as a Learning Service Center on the Internet is the construction of server hardware facilities that serve several local lines, internet and INHERENT. Internet server that serves the general Internet network, INHERENT server that serves the network between universities in Indonesia and Local Server that serves a special network in the Department of Education Technology State University of Malang. Other Information and Communication Technology tools are also developed, among others, broadcasting technology.

Hardware requirements as a tool for the development of web-based learning has been given priority in the Department of Education Technology State University of Malang. The hardware requirements include on-line access service devices. Other hardware is a service device to the academic community to be able to perform free internet access and internet on computers that netted internet and intranet interconnection and provision of access point devices for users using personal mobile devices. In hardware development there is need of management and standard rules of use of infrastructure services resulting from analysis to evaluation of hardware implementation in web-based lectures on the on-line system at the institution

Brainware needs as a web-based learning developer also get priority in the Department of Education Technology State University of Malang. The developer's needs include developing the concept and implementation of web-based on-line learning system. The concepts and implementations applied so far in the development of learning systems at the Department of Education Technology State University of Malang derived directly from the implementation of information technology. Rules, 
aspects and theories of learning are not at all a consideration of the development of learning and learning resources.

Department of Education Technology State University of Malang in leading to the development of learning also has constraints. These obstacles are 1) the use of on-line learning media is still seen running alone has not been done in an integrated and coordinated at the administrative level. This is seen still using a separate web-web such as Yahoo, Google, Massangger dll. Technically the Department of Educational Technology State University of Malang does not have a platform that becomes the benchmark and standard development of learning media. 2) Together with lecturers are still busy in managing learners in learning activities. Good in activities scheduling space, faculty and students. This is due to the increasing number of less learners with the capacity to accommodate Pebelajar and learning resources. 3) The investment of on-line learning software is not a very expensive infestation. This is because the license is imposed because of system usage.

\section{CLOUD COMPUTING IN LEARNING}

Universities around the world are mostly beginning to depend on information and communication technologies to serve the needs of learning and learning activities. (Wing Lai: 2011) The use of information and communication technology supports the shift of cultural practices in the teaching and learning process in universities. The use of information technology is also to better meet the needs of the 21 st century users of academics of higher education. Information technology and digital communications can provide a more active and flexible learning experience by adopting a participatory pedagogical approach and by integrating formal learning with informal learning. Various advantages and disadvantages are packets that are perceived as a risk of using technology.

Developing countries in Southeast Asia are increasingly recognizing the important role of higher education institutions in increasing their resources through the use of Information and Communication Technology. (Hong and Songan: 2011) The higher education system in the Southeast Asian region is increasingly utilizing ICT in addressing emerging challenges. The challenges are 1) what and how students learn , 2) when and where students learn, and 3) ways to reduce the cost of education. Countries in Southeast Asia are at different stages of development with developed countries in the use of Information and Communication Technology in higher education. Therefore,
Technology in the "cloud computing" system is the advancement of information and communication technology. The promised package is a promising economical scale and a feature that is able to improve institutional services. The latest issue is the "cloud computing" service system is growing and provided unpaid and using only Internet technology. Users from academics such as faculty, students, staff and policy makers can take advantage of the "cloud computing" system by accessing from the provided web browser. The services offered can be considered cheap or even free for education. In many ways even the availability of services is higher and better than can be provided by Higher Education.

Great designs have been implemented by internet service providers. Future technology trends are beginning to lead to the majority of educational, learning and learning services going through "cloud computing". Institutions as part of the global world no longer host their own data centers due to expensive hardware investments, swollen electricity bills, manager salaries and many rarely exploited features. The development of the "cloud computing" system is a masterpiece for realizing globalization.

\section{SERVICE PACKAGE ON CLOUD COMPUTING SYSTEM}

The "cloud computing" system offered by various internet service providers has several packages. Some of the packages are:

Services on "Cloud computing" systems delivered over the Internet from high-specific data centers are built in locations far from university users and institutions. The server providers already have the features they have invested in the latest cooling systems and service optimization techniques. If this investment is done by a college, it will burden the budget system significantly. The data centers developed by service providers are in locations that are near cheap power sources. Even data center locations are not always known to users, although in some cases users need services that are located in certain countries due to data protection laws. Service providers provide access rights and control over data stored through the "cloud computing"

Key service features such as data storage, processing, memory and bandwidth are shared proportionally with multiple users and can be dynamically allocated until services can be allocated based on demand. The hardware components provided by the service provider can be replaced without impacting the learning service, learning, performance or even availability of new space. The management of data scattered across multiple data centers in the category is safe because the service provider provides the latest system security and robustness. 
The main service feature of the "cloud computing" system is elastic and fast. This factor allows college and academic managers who use the "cloud computing" system to suddenly request service. The "cloud computing" system that has been implemented to date has given the impression that the management of the service is scalable but capable of providing infinite service to the users. The easiest explanation is If colleges and academic users want to increase their usage suddenly there should be no need to file or purchase additional hardware that can take weeks and then can be fully utilized.

The management of budget allocation is the most interesting issue in the use of "cloud computing" systems. If the "cloud computing" system requires a budget allocation, then the user only pays for the services used. Service providers will bear the cost of hardware and software provision. In some of the features provided on the "cloud computing" system, using unpaid features. Thus, the Service Provider will bear fully against the cost of hardware and the provision of the software.

In general, the management of services by users can be done by self-managed. Users can decide what features to use, and add or subtract this without having to discuss with the service provider. Reporting facilities are provided so customers can monitor feature usage.

\section{CLOUD COMPUTING IMPLEMENTATION}

Some education providers and even universities who have used on-line learning and learning services, have not used the system "cloud computing" optimally. Some universities have even mistakenly assumed the "cloud computing" system. The assumption on a "cloud computing" system is a system on the Internet that does not provide much support for learning and learning and only facilitates activities not held by universities. Universities are even confused between the term Web 2.0 and the "cloud computing" system.

The theory of "cloud computing" has not yet got agreement in the global understanding. This also applies to web 2.0 technology. Blogs, wikis, twitter, facebook and others are technologies that are considered as Web 2.0 apps. Web 2.0 technology applications allow users to change the content of web pages and interact with others through the application to create 2-way information and communication constructions.

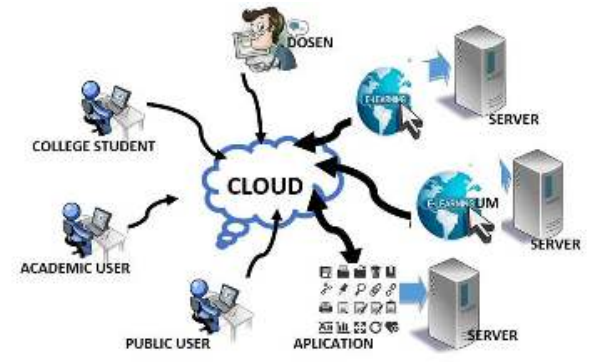

Figure 3. Cloud Computing TEP UM

Web 2.0 software can be hosted by Colleges through an intranet or generally accessible via the Internet. In this context, Web 2.0 can be considered a certain type of application whereas "cloud computing" is a system that allows multiple methods in various applications that allow for storage, processing, management, delivery activities.

\section{CLOUD COMPUTING ON LEARNING SYSTEM}

The learning system is a major force in educational institutions in general. Universities are institutions of higher education that have a diversity of services in the learning system. The trend of college service is a service with the headline "elearning". Various versions of elearning applications have been utilized as a means in the learning system. The e-learning nuance colored every theory, model and even discussion and research studies. So that e-learning is a superior service application in a learning system in Higher Education.

Modern learning systems can not be monopolized institutions and tend to be flexible to the type and location of learning resources. Higher Education is not possible to close two-way access with service providers on the Internet. Even user entities are not just among the academic community. So "clutter" in the era of learning has been anticipated by a very large system of "cloud computing". Exceptional strength has emerged and is ready to be applied in Higher Education learning systems.

\section{CONCLUSIONS}

In general, the development of web-based learning opensource platform on the subject of computer learning S-1 Department of Educational Technology State University of Malang can produce learning media products that utilize web-based cloud computing in accordance with the characteristics of learning resources, learning content, learners, learning strategies and learning methods In the context of Undergraduate Students of Department of Educational Technology State University of Malang 


\section{REFERENCES}

[1] Brands, JA (1982). Adoption and Implementation of (Micro) computers in School Organizations in Computers in Education. In Lewis, B. \& Tagg, D. (Eds), Proceedings of the IFIP, Panel Discussions , Third World Conference on Computers in Education, North-Holland, p. 820.

[2] Guleria . Pratiyush, Sharma. Vikas, Arora. Manish. Development and Usage of Software as a Service for a Cloud and Non-Cloud Based Environment An Empirical Study. International Journal of Cloud Computing and Services Science (IJ-CLOSER). Vol.2, No.1, February 2013, pp. $50 \sim 58$

[3] Hedberg, JG \& Harper, B. (1992). Information Systems Strategy in the Small Educational Organization, In Windley, G. \& MacGregor, R, Eds., 3rd Australian Conference on Information Systems , ACS, University of Wollongong, October.

[4] Hong.Kian-Sam and Songan. Peter. 2011 ICT in the changing landscape of higher education in Southeast Asia . Australasian Journal of Educational Technology 2011, 27 (Special issue, 8), 1276-1290.

[5] King, JL (1987). A Practical Assessment of Computerization in Schools In Bank, A. \& Williams, RC, Eds. Information Systems and School Improvement: Inventing The Future . New York: Teachers College Press, pages 119-135.

[6] Kwok-Wing Lai. 2011. Digital technology and the culture of teaching and learning in higher education. Australasian Journal of Educational Technology , 27 (Special issue, 8), 1263-127 5

[7] McFadden, F. \& Hoffer, AT (1991). Database Management . New York: Benjamin / Cummings.

[8] McShane, R., Fitzgerald, D., Halliwell, G., Penter, K., Richards, H., Smulders, M. \& Woodrow, D. (1986). Australian School Computer Systems - Educational User Requirements: Appendix 1: Administrative Applications of Computers in Schools . National Advisory Committee on Computers in Schools: Report to the Commonwealth Schools Commission, pp. 25-27.

[9] Reddy. Krishna. Security Architecture Of Cloud Computing. International journal of engineering science and technology (IJEST). Vol. 3 No. September 9, 20117149 - 7155

[10] Sclater. Niall. 2010. Cloud Computing in Education. Unesco Institute for Information Technologies in Education. Moscow. Russian Federation.

[11] Stecher, B. (1987). Superintendents do not type advice for those setting up IIS training programs for administrators. In Bank, A. \& Williams, RC (Eds.), Information Systems and School Improvement: Inventing The Future . New York: Teachers College Press, Page 159-166.

[12] Williams, RC \& Bank, A. (1987). Realities and Scenarios: Instructional Information Systems in the Classrooms of the Future. In Bank, A. \& Williams, RC (Eds.), Information Systems and School Improvement: Inventing The Future . New York: Teachers College Press, Page 145-151. 